\title{
regras para a concepção de um monumento contemporâneo: porque o Museu Nacional Honestino Guimarães é um monumento
}

\author{
Arthur Gomes ${ }^{1}$
}

\section{Resumo}

O presente trabalho se propõe a questionar, de acordo com textos já consolidados, a criação e representatividade de monumentos históricos e arquitetônicos no contexto contemporâneo. Para isso propõe-se um conjunto de regras criadas a partir de uma avaliação de um monumento particular, objeto de estudo desse trabalho, o Museu Nacional Honestino Guimarães - MUN, localizado em Brasília é tombado, juntamente com o Setor Cultural Sul, este, por sua vez, dentro da escala monumental de Lucio Costa. Para a elaboração dessas regras foram levados em consideração os valores de monumento do autor Alois Riegl, a legislação de tombamento e as definições consolidadas de Monumento. Essas recomendações orientam a concepção de um monumento arquitetônico. Questionando os valores, definição e tombamento, chega-se a conclusões referentes ao caráter de monumento

\footnotetext{
${ }^{1}$ Graduando em museologia pela Universidade de Brasilia - UnB, pesquisador do grupo "Museologia, Patrimônio e Memória", pesquisa as temáticas do patrimônio, monumento, ressignificação e cultura visual.
} 
METAgraphias: letra F de \#foulipo (criação potencial) v.2 n.3 setembrol2017 regras para a concepção de um monumento contemporâneo • Arthur Gomes (arthurgbar@gmail.com)

do MUN, conquistado pela mão que o fez.

Palavras-chave: Monumento; Museu Nacional de Brasília; Oscar Niemeyer; Patrimônio

\section{Abstract}

This article proposes to question, according to already consolidated texts, the creation and representativeness of historical and architectural monuments in the contemporary context. For this purpose, a set of rules created from an evaluation of a particular monument, object of study of this work, is proposed, the Honestino Guimarães National Museum - MUN, located in Brasilia and listed as heritage along with the South cultural sector. For the elaboration of these rules were taken into account the monument values of the author Alois Riegl, the legislation of heritage and the consolidated definitions of Monument. These recommendations guide the creation of a monument. Questioning the values, definition and the heritage, one arrives at the conclusions referring to the character of monument of the MUN. Allowed by the hand who build it.

Keywords: monument; national museum of Brasília; Oscar Niemeyer; heritage

Ao avaliarmos criticamente a construção monumental da cidade de Brasília e os monumentos abrigados em seu espaço urbano, em especial aqueles projetados pelo arquiteto Oscar Niemeyer, levando aqui em consideração a definição literal de Monumento, identifica-se um caráter diferenciado para o uso da qualidade e classe de monumento.

O autor dos prédios monumentais da capital foi responsável pelo pedido de tombamento, 
METAgraphias: letra F de \#foulipo (criação potencial) v.2 n.3 setembrol2017 regras para a concepção de um monumento contemporâneo • Arthur Gomes (arthurgbar@gmail.com)

junto ao Instituto Histórico e Artístico Nacional, IPHAN, de um conjunto de 27 obras suas², assim, avaliamos o que qualifica suas obras como monumentais.

Caso esteja interessado em conceber um monumento para uma praça, para uma rua, ou qualquer espaço público, lugar, local de grande trânsito e movimentação social, eis aqui algumas regras:

1. O monumento deve ser grande. Independentemente de qualquer outra coisa $\circ$ monumento deve ser grande. Se o espaço não permitir, procure outro. Se ainda assim não for possível atingir o grau desejado de grandiosidade através do tamanho, a estrutura em questão deve ser grande em termos simbólicos, execução técnica ou capacidade de chamar atenção. Mas se for grande em sua dimensão, é o ideal.

2. Deve ser excepcional. A unicidade e originalidade do monumento é ainda mais importante que a sua grandiosidade. É de extrema importância que ele seja excepcional. De extremo rigor técnico e criatividade nunca antes vista.

3. Abuse da poética. Mesmo que um monumento esteja relacionado a um marco histórico e a necessidade de rememoração, abuse da poética de uma forma a tornar ininteligível o significado daquela construção. Livre-se de legendas e qualquer explicação sobre a construção.

4. Use, de preferência, concreto e metal. Vidro quando for possível. Desenvolva também soluções arquitetônicas inovadoras e mantenha suas inspirações próximas ao moderno e contemporâneo. A época do barroco já passou, e o lphan tende a não simpatizar muito com

\footnotetext{
${ }^{2}$ Informação disponível em <http://www.cultura.gov.br/noticias-destaques/lasset publisher/OiKX3xIR9iTn/content/minc-efetiva-processo-de-tombamento-de-27-obras-deniemeyer/10883> Acesso em 18/10/2017.
} 
METAgraphias: letra F de \#foulipo (criação potencial) v.2 n.3 setembrol2017 regras para a concepção de um monumento contemporâneo • Arthur Gomes (arthurgbar@gmail.com)

estilos como o eclético.

5. Crie um espaço, melhor que seja um lugar, cheio de aura, para que a construção se torne intocável. Fica mais fácil se você for Niemeyer.

Pronto, siga estas regras, desenhe cerca de trinta esboços diferentes, todos de linha contínua, traços rápidos, fluidos e um pouco incompreensíveis, construa, e solicite o tombamento da sua obra. O cumprimento das recomendações resultará em um monumento.

As regras estipuladas acima de forma irônica foram pensadas após reflexões acerca das definições e representatividade dos monumentos, em especial o Museu Nacional da República - MUN, de autoria conceitual do já mencionado Oscar Niemeyer, o prédio foi projetado para abrigar um museu, e já estava previsto desde a década de 1950 por Lucio Costa, no entanto só começou a ser construído em 1999, tendo sido concluído em 2006.

As reflexões aqui mencionadas se originaram após pesquisas referentes a natureza de Monumento do museu, seus processos de ressignificação e significância social, discussão que desenvolvi em um outro artigo ${ }^{3}$, de forma mais delimitada, mas que abriu espaço para outros questionamentos.

Perceber o museu como um monumento, após entendimento do que é esta definição, dos valores que estes carregam e de sua significação dentro da sociedade é acontecimento complexo que deixa uma serie de inquietações quando nos debruçamos sobre as definições de monumento e por sobre o caráter excepcional do objeto aqui estudado, uma das obras brasilienses de Oscar Niemeyer.

\footnotetext{
${ }^{3} \mathrm{O}$ artigo em questão foi desenvolvido dentro do programa de iniciação cientifica da Universidade de Brasília, orientado pela Profa.Dra. Ana Lucia de Abreu Gomes. Intitulado "Ressignificando Concreto: relações entre monumento e arte" está para avaliação do programa PIBIC/CNPq/UnB
} 
METAgraphias: letra F de \#foulipo (criação potencial) v.2 n.3 setembrol2017 regras para a concepção de um monumento contemporâneo • Arthur Gomes (arthurgbar@gmail.com)

Comecemos então com as definições de monumento para então refletirmos a respeito do prédio do museu. É monumento

Tudo o que for edificado por uma comunidade de indivíduos para rememorar ou fazer que outras gerações de pessoas rememorem acontecimentos, sacrifícios, ritos ou crenças. A especificidade do monumento deve-se precisamente ao seu modo de atuação sobre a memória. Não apenas ele a trabalha e mobiliza pela mediação afetiva, de forma que lembre o passado fazendo-o vibrar como se fosse presente (CHOAY,1925, p.18),

Um monumento tem ainda, como sentido primário, a qualidade de ser estrutura onde vive a memória, definido pelo autor austríaco Alois Riegl como "[...] obra criada pela mão do homem e elaborada com o objetivo determinante de manter sempre presente na consciência das gerações" (RIEGL, 2014 p.31), continuamos com as definições, "é onde a memória está viva. Deve estar sobre a terra e necessita de pessoas vivas que lembrem e outorguem sua existência e a justifiquem" (BARBOSA A.G, 2017). E por fim, analisando a própria etimologia da palavra temos

A palavra latina monuentum remete para a raiz indo-europeia men, que exprime uma das funções essenciais do espirito (mens), a memória (memini). O verbo monere significa "fazer recordar", de onde "avisar", "iluminar, "instruir". O monumentum é um sinal do passado. Atendendo às suas origens filológicas, o monumento é tudo aquilo que pode evocar o passado, perpetuar a recordação, por exemplo, os atos escritos. (LE GOFF, 1990, p. 462)

Segundo as duas definições mais aceitas e consolidadas de monumento, a primeira aqui citada trazida por Françoise Choay e a segunda de Riegl, a estrutura em questão deve ser idealizada com um valor de memória, já que, por definição, aquilo que nós conhecemos por monumento é uma "[...] construção ou obra que transmite a recordação de alguém ou de

\footnotetext{
${ }^{4}$ Riegl foi convidado para redigir seu texto em 1903, no entanto, a tradução brasileira data, tardiamente, de 2014.
} 
METAgraphias: letra F de \#foulipo (criação potencial) v.2 n.3 setembrol2017 regras para a concepção de um monumento contemporâneo • Arthur Gomes (arthurgbar@gmail.com)

algum fato memorável"5. A própria palavra, como explicita Le Goff, está relacionada ao lembrar.

Assim, como podemos falar do edifício do MUN como um monumento? Ele foi criado com a intenção de lembrar ou marcar algum fato? Seria ele um lugar de memória?

Tal inquietação se apresenta quando refletimos a respeito da construção do prédio e sobre os chamados valores de Riegl. E temo ainda que a resposta dessa questão, sobre sua criação com intenção de memória, seja aqui negativa.

O Museu Nacional é um monumento histórico tombado dentro do conjunto cultural sul (processo $\left.{ }^{\circ} \mathrm{T}-1550-07\right)$, complexo previsto em Relatório do Plano Piloto, e projetada pelo arquiteto Oscar Niemeyer, inaugurado por fim em 2006.

Sua construção é comemorativa e não rememorativa. Este prédio existe por sua função de museu, pela necessidade da capital da República de ter um grande museu dentro de seu eixo monumental que é o que, segundo Lúcio Costa, garante à cidade de Brasília, o status de capital.

Dizemos comemorativa, pois está associado a uma ideia de enaltecer a capital da República, no entanto, não marca, em termos de memória, nenhum acontecimento memorável ou fato histórico. Assim, devemos questionar seu local de monumento e também de um lugar de memória, nos valendo aqui dos conceitos estipulados pelo autor francês Pierre Nora.

A expressão "lugar de memória" do qual o autor se utiliza se refere a um processo datado de fins do século $X X$, em que os lugares de memória existem porque não há mais meios de se rememorar. Para Nora, o lugar de memória deve ser funcional, simbólico e material, um ponto

\footnotetext{
${ }^{5}$ Definição retirada da versão online do dicionário Aurélio, disponível em https://dicionariodoaurelio.com/monumento acesso em 18/10/17
} 
METAgraphias: letra F de \#foulipo (criação potencial) v.2 n.3 setembrol2017 regras para a concepção de um monumento contemporâneo • Arthur Gomes (arthurgbar@gmail.com)

onde se cristaliza uma parte de uma memória nacional. No caso do MUN, é possível aproximalo da condição de lugar de memória quando pensamos no contexto da construção de Brasília e em sua funcionalidade, mas ainda não como monumento. Tal pensamento pode, entretanto, beirar um certo anacronismo, uma vez que a construção do prédio é bem posterior a da cidade. Seguimos então a tentar qualificar a obra como monumento, para isso, passaremos a discutir o autor Alois Riegl.

Os já citados valores de Riegl são fruto de um estudo desenvolvido pelo autor para o governo austríaco, pós Revolução Francesa, em que analisa os monumentos europeus dos séculos XIX e XX e identifica um conjunto de características e classes que entendidas como valores servem para melhor conhecer a natureza do monumento. Vale ressaltar que os valores elencados no trabalho do autor, "O Culto Moderno dos Monumentos", são atribuídos a posteriori enquanto as definições de monumento indicam a necessidade de um valor memorável a priori.

Cabe ressaltar que o objeto de estudo deste trabalho é um monumento histórico. E um monumento histórico é aquele que se encontra morto, ou seja, que não é lembrado, que não guarda memória e que precisa de um discurso que o explique.

Sendo ainda histórico aquele valor relacionado a própria noção de história:

\footnotetext{
Chamamos de histórico, tudo o que foi e que não é mais nos dias de hoje. De acordo com os conceitos mais modernos, acrescentamos a isso a ideia de que aquilo que foi não mais poderá voltar a ser nunca mais e tudo que foi forma o elo insubstituível e irremovível de uma corrente de evolução ou, em outras palavras, tudo que tem uma sequência supõe um antecedente e não poderia ter acontecido da forma como aconteceu se não tivesse sido antecedido por aquele elo anterior (RIEGL, 2014 p.32)
}

Ou seja, em um primeiro momento, se nos basearmos na definição de monumento histórico, veremos que o MUN não se encaixa exatamente uma vez que é uma obra recente, de "ontem", finalizada em 2006 e possuidor de uma arquitetura moderna, que ainda é. 
Porém ao considerarmos o MUN como obra arquitetônica que foi possibilitada graças aos avanços tecnológicos, estilísticos e conceituais da história da arquitetura, configura-se e confirma-se o primeiro valor do museu, valor histórico, uma vez que este só se tornou real graças ao que foi desenvolvido anteriormente ao seu projeto e durante, pois, como já mencionado em nossas regras, é importante desenvolver soluções arquitetônicas únicas, deixando desafios aos engenheiros calculistas. Podemos então dizer que o edifício possui o valor histórico de monumento.

Como já mencionado, este valor necessita de uma associação a um discurso, que aqui é o da construção da capital, Brasília, mas que não se relaciona diretamente ao prédio, nem às suas formas.

Seguimos então a levantar os valores de monumento contidos no MUN. Já entendemos que o prédio possui o valor histórico. Além disso, possui valor de uso, valor artístico e de novidade.

Sendo o valor de uso aquele relativo aos usos práticos e funcionais do monumento, aqui um museu; o valor artístico relacionado à "vontade de $\operatorname{arte}^{6}$ da época, aqui, a arquitetura moderna; e o valor de novidade se relaciona à existência de algo incomum, chamariz de olhares e que se qualifica como melhor que o velho.

São esses os valores de monumento que conseguimos atribuir ao museu. Mas seriam esses suficientes para qualificá-lo como monumento mesmo com a ausência de memória? Para responder essa questão, desenvolvemos as regras para a concepção de um monumento arquitetônico contemporâneo.

Relembrando, aqui estabelecemos cinco direcionamentos: primeiro, que seja grande.

\footnotetext{
${ }^{6}$ Originalmente Riegl fala de kunstwollen, que define como a vontade de arte de uma sociedade em um tempo especifico. O termo aparece em trabalhos como "Problema de Estilo" e "O Culto Moderno dos Monumentos.
} 
METAgraphias: letra F de \#foulipo (criação potencial) v.2 n.3 setembrol2017 regras para a concepção de um monumento contemporâneo • Arthur Gomes (arthurgbar@gmail.com)

Segundo, excepcional. Em terceiro lugar, deve ser poético, em quarto, precisa-se de atenção quanto aos materiais, sugerimos concreto, metal e vidro. E por fim, deve estar inserido em um lugar cheio de aura.

Passada a discussão a respeito do monumento, voltamo-nos agora à estas recomendações. Analisemos a primeira regra: o edifício é de grande dimensão. Ocupa, dentro dos 91,8 mil metros quadrados do complexo cultural sul, parte dos 11 mil metros quadrados ${ }^{7}$ de área edificada, está localizado em um local-construção, o eixo monumental e esplanada dos ministérios de Lucio Costa que é projetado e definido como também monumental "[...] não no sentido de ostentação, mas no sentido da expressão palpável, por assim dizer, consciente, daquilo que vale e significa" (COSTA, 1991 p.22). No entanto, não significa efetivamente, a priori, nada pois o MUN é um monumento vazio de sentidos simbólicos e memoráveis que orientem sua construção. Ainda assim é grande.

Além disso, a obra é grandiosa pelo seu contexto: concebida pelo também grande Oscar Niemeyer, para a capital da República. É carregada de um valor simbólico e histórico, possuindo assim a tal aura monumental, presente tanto no prédio quanto no autor.

Configura-se como parte do imaginário imagético urbano de Brasília, cartão postal, como uma grandiosa escultura moderna. E

Parece que a lógica da escultura é inseparável da lógica do monumento. Graças a esta lógica, uma escultura é uma representação comemorativa - se situa em determinado local e fala de forma simbólica sobre o significado ou uso deste local" (KRAUSS, 1979, p.131).

Assim, "as esculturas funcionam, portanto, em relação à lógica de sua representação e de seu

\footnotetext{
${ }^{7}$ As informações quanto as dimensões do complexo foram extraídas de sitio do GDF que conta a história do museu. Disponível em http://www.cultura.df.gov.br/historia-do-museu-nacional.html, acesso em 19/10/17
} 
METAgraphias: letra F de \#foulipo (criação potencial) v.2 n.3 setembrol2017 regras para a concepção de um monumento contemporâneo • Arthur Gomes (arthurgbar@gmail.com)

papel como marco [...] importantes por fazerem a mediação entre o local onde se situam e o signo que representam". (KRAUSS, 1979, p.131). Então, através das falas de Krauss, o museu recebe a roupagem de escultura por mediar a cidade, seu contexto histórico e arquitetônico, e seu autor. Novamente com um valor comemorativo.

Pensando então a estrutura como monumento e escultura, seguimos para o autor DidiHuberman, quando pensamos que o que nós vemos só se torna real quando nos olha. Ou seja, o MUN, enquanto escultura e monumento se torna escultura e monumento quando os olhares a ele direcionados o entendem como tal. A grandeza da obra passa então uma ideia de monumentalidade, e possibilita, uma vez que se entende através dessa ideia o edifício como monumento que ele assim se apresente.

Uma vez feita essa reflexão, evidenciamos como a estrutura segue as determinações da primeira regra e partimos então para a segunda orientação inicialmente listada: o monumento deve ser excepcional.

Dentro do contexto brasiliense a excepcionalidade do museu, sua unicidade, é real. É, no conjunto da esplanada, uma obra única. No entanto, ao analisarmos o resto da produção artística do arquiteto responsável percebe-se que a originalidade da obra é compartilhada. As formas se repetem, como por exemplo na Oca, localizada no Parque do Ibirapuera na cidade de São Paulo. Porém, graças à primeira regra e ao autor, continua excepcional, fazendo parte de uma serie, uma grife de esculturas monumentais.

A excepcionalidade é também importante para o tombamento do monumento, já que o que vemos na legislação do tombamento, Decreto-Lei $n^{\circ} 25$ de 1937, que diz respeito ao patrimônio nacional, em parágrafo primeiro é:

Art. $1^{\circ}$ Constitui o patrimônio histórico e artístico nacional o conjunto do móveis e 
METAgraphias: letra F de \#foulipo (criação potencial) v.2 n.3 setembrol2017 regras para a concepção de um monumento contemporâneo • Arthur Gomes (arthurgbar@gmail.com)

imóveis existentes no país e cuja conservação seja de interesse público, quer por sua vinculação a fatos memoráveis da história do Brasil, quer por seu excepcional valor arqueológico ou etnográfico, bibliográfico ou artístico (BRASIL, 1937,n/p)

Novamente, a presença do valor de memória é mencionada, mas além disso, a excepcionalidade se configura como fator determinante para a constituição do patrimônio, e entendendo que o patrimônio diz respeito também ao monumento, que a excepcionalidade é necessária ao monumento e o MUN é de fato excepcional.

Seguimos então para a terceira regra, o abuso da poética, que no caso do MUN e de numerosos prédios do arquiteto Niemeyer é uma poética de formas puras, simples, funcionais, mesmo quando essa funcionalidade não condiz com a função primaria do prédio. No caso do museu, as formas geram alguns problemas quanto à acessibilidade, expografia e outras questões museológicas, mas essas não serão aqui elencadas pois estamos tentando entender o que faz do museu um monumento, e não um museu. O que nos interessa é como a forma é importante tanto para a excepcionalidade quanto para a poética.

Entendendo que um monumento é um marco de acontecimentos memoráveis, de interesses, que reaviva a memória, que são testemunhas, cristalizadores de mentalidades temporais, de um espaço-tempo especifico, é possível se estender sobre suas relações posteriores, onde as significâncias são alteradas ao longo das épocas.

Ora, apesar de alocado em um contexto temporal específico, o monumento transcende a temporalidade de seus idealizadores. Assim, sobrevive a épocas de significâncias inimagináveis àqueles que o edificaram. Podemos pensar em como suas formas e sua estrutura se responsabilizam também pela manutenção das questões apresentadas. No entanto, o prédio, a priori, não significa nada, suas formas nada lembram a não ser o contexto específico da construção de Brasília e a estética construída pelo seu arquiteto. Porém, quando pensamos 
METAgraphias: letra F de \#foulipo (criação potencial) v.2 n.3 setembrol2017 regras para a concepção de um monumento contemporâneo • Arthur Gomes (arthurgbar@gmail.com)

nas formas que se repetem em outras edificações em diferentes localidades percebe-se uma fissura na comunicação das ideias referentes ao monumento, um ruído na intenção de significância e marco. E assim seguimos, pois, suas formas estão justificadas na poética.

Associada à terceira regra está a quarta, uma vez que a poética também direciona o uso dos materiais a serem utilizados. Esses se responsabilizarão pelo efeito visual da estrutura, pela mediação da atenção e também pelos volumes. E uma grande estrutura de concreto é certamente volumosa. E "[...] a relação Volume $\times$ Vazio também traz questões sobre o que vemos e principalmente sobre o que nos toca. O volume ressuscita ideias (DIDI-HUBERMAN, 2010, p. 43).

É muito importante conceber estruturas de grandes volumes, de preferência cheio, concretos, sem muitas interrupções, para que esses prendam a atenção, e expressem, mais uma vez, a ideia de monumento contida na grandiosidade.

Por fim, é necessário que a estrutura tenha aura. Que a ideia da edificação permeie diferentes imaginários. Para isso, nada melhor que inserir o monumento em um lugar, de preferência de grade trânsito, onde relações sejam criadas e experenciadas. No caso estudado, atingir a última recomendação chega a ser relativamente fácil.

O lugar Brasília e o complexo cultural sul já possuem uma aura própria. Além disso, o autor do edifício carrega suas construções com uma potência mítica, diferenciada, proporcionada pela fama do arquiteto. Toda obra de Niemeyer é, obviamente, uma obra de Niemeyer.

O edifício já vem carregado da aura mencionada e se torna também um lugar diferenciado, intocável, tal como diz a legislação de tombamento, no art.17:

As coisas tombadas não poderão, em caso nenhum ser destruídas, demolidas ou mutiladas, nem, sem prévia autorização especial do Serviço do Patrimônio Histórico e 
Artístico Nacional, ser reparadas, pintadas ou restauradas, sob pena de multa de cinquenta por cento do dano causado (BRASIL, 1937, n/p)

A lei continua corroborando com as ideias aqui apresentadas quando, em parágrafo único, referente aos art. 6 e 10, afirma que "para todas os efeitos, salvo a disposição do art. 13 desta lei, o tombamento provisório se equiparará ao definitivo" (BRASIL, 1937, n/p). Logo, todo patrimônio efetivo ou provisório está protegido, intocável. Seguidas então todas as regras, está configurado o monumento.

Seguimos então para as considerações finais desse escrito, onde definimos monumento e comentamos brevemente sua importante e intrínseca relação com a memória, com o lembrar, e com acontecimentos.

Traçado esse caminho, apresentamos o contexto do nosso objeto, Museu Nacional de Brasília, e como esse, teoricamente, não atende à definição inicial de monumento. Elencamos então os valores que o possibilitam ser qualificado e estabelecemos, após análise do objeto, regras ou recomendações para a concepção e construção de um monumento arquitetônico contemporâneo, para questionar a definição de monumento dada ao MUN e outorgada pelo tombamento do prédio.

Chega-se então à conclusão especulativa de que $\circ$ que $\circ$ faz realmente monumento $e$ monumental é, acima de sua adequação às regras aqui estabelecidas, a mão que o fez, pois identifica-se em seu autor uma qualidade de Midas, já que tudo o que por ele é feito é passível de tombamento e "monumentalização", fato evidenciado pela homologação em 2017 do tombamento de 27 obras do arquiteto localizadas em Brasília, Rio de Janeiro e São Paulo. O 
METAgraphias: letra F de \#foulipo (criação potencial) v.2 n.3 setembrol2017 regras para a concepção de um monumento contemporâneo • Arthur Gomes (arthurgbar@gmail.com)

processo foi iniciado no ano de 2007 e nasce da vontade do próprio Niemeyer ${ }^{8}$ aprovado pelo conselho consultivo do patrimônio cultural do Instituto do Patrimônio Histórico e Artístico Nacional - IPHAN.

Antes mesmo de se adequar a definição de monumento e aos conceitos aqui apresentados, - MUN, tal como o Museu de Arte Contemporânea MAC-Niterói, Oca, e Museu Oscar Niemeyer -MON em Curitiba entre outros, são obras de Niemeyer.

Além disso, no caso do MUN e do contexto histórico do seu local, a sua qualificação como monumento pode ser aproximada de uma concordância com as ideias apresentadas por Le Goff, que afirma que

Desde a Antiguidade romana o monumentum tende a especializar-se em dois sentidos: 1) uma obra comemorativa de arquitetura ou de escultura: arco de triunfo, coluna, troféu, pórtico, etc [...] (LE GOFF, 1990, p 462)

Pensando então o edifício como comemorativo da construção e existência da cidade de Brasília, pode-se qualifica-lo como um monumento, apresentada a tendência desses de se afastarem da memória e comemorarem.

A função maior deste artigo é, por fim, gerar questionamentos a respeito da representatividade social dos monumentos em termos de memória e consciência de significado, do seu valor social e dos critérios para a classificação e qualificação de um monumento, tal como os critérios de tombamento. Apresentando um caso especifico que ilustra a fluidez dos critérios e definições de tombamento e monumento através de um texto de intenção provocativa.

\footnotetext{
${ }^{8}$ Esta afirmação está disponível em http://www.cultura.gov.br/noticias-destaques/lasset publisher/OiKX3xIR9iTn/content/minc-efetiva-processo-de-tombamento-de-27-obras-deniemeyer/10883 acesso em 20/10/217
} 
METAgraphias: letra F de \#foulipo (criação potencial) v.2 n.3 setembrol2017 regras para a concepção de um monumento contemporâneo • Arthur Gomes (arthurgbar@gmail.com)

Pensando o monumento como representativo da sociedade, o convite feito aqui é o de repensar essas estruturas e retraduzir sua significância, incentivando a ressignificação e apropriação desses que devem ser marcos de nossas histórias.

\section{REFERÊNCIAS}

BARBOSA, A.G. Ressignificando concreto: relações entre o monumento arte. Brasília, 2017. Disponível em $<$ http://proic.unb.br/index.php?searchword=anais\&searchphrase=all\&ltemid=161\&option=com_search> No prelo.

BRASIL. Decreto-Lei n²5, de 30 de novembro de 1937. Organiza a proteção do patrimônio histórico e artístico nacional. Diário Oficial, Rio de Janeiro, RJ, 30 nov. 1937. Disponível em: <http://portal.iphan.gov.br/uploads/legislacao/Decreto_no_25_de_30_de_novembro_de_1937.pdf> Acesso em 18/10/2017.

CHOAY, Françoise. A alegoria do patrimônio; Trad. Luciano Vieira Machado. $4^{\circ}$ ed.- São Paulo: Estação Liberdade: UNESP, 2006. 288p.: il.

DIDI-HUBERMAN, Georges. O que vemos, o que nos olha; Trad. Paulo Neves - São Paulo: Editora 34, 2010 (2 Edição).

DIDI-HUBERMAN, Georges. Quando as imagens tocam o real; Trad. Patrícia Carmello e era Casa Nova. Pós: Belo Horizonte, v 2, n.4, p $204-219$. Nov, 2012.

HOLANDA, Aurélio Buarque de. Monumento. Dicionário Online Aurélio. 2017. Disponível em: <https://dicionariodoaurelio.com/monumento> Acesso em: 18/10/17.

KRAUSS, Rosalind. A escultura no campo ampliado; Gávea n.1, PUC-Rio, 1984 (87-93).

LE GOFF, Jacques. História e Memória; Trad. Bernardo Leitão. Campinas, São Paulo. Editora da UNICAMP, 1990.

RELATÓRIO do Plano Piloto de Brasília/ elaborado pelo ArPDF, CODEPLAN, DePha - Brasília: GDF, 1991. 76p., il. Disponível em <http://www.brasiliapoetica.blog.br/site/media/relatorio_plano_piloto_de_brasilia_web2.pdf> Acesso em 18/10/2017.

NORA, Pierre. Entre memoria e história: a problemática dos lugares. Trad. Yara Aun Khoury, São Paulo; Projeto História v.10, PUC-SP $1993 . \quad$ Disponível em <https://revistas.pucsp.br/index.php/revph/article/view/12101/8763> Acesso em 19/10/2017.

RIEGL, Alois. O culto moderno dos monumentos: a sua essência e a sua origem; Trad. Werner Rothschild Davidsohn, Analt Falbel - I.ed.- São Paulo: Perspectiva, 2014. 88p. 